Lee, S.-L., Park, M. S.-A., \& Tam, C.-L. (2015). The relationship between Facebook attachment and obsessive-compulsive disorder severity. Cyberpsychology: Journal of Psychosocial Research on Cyberspace, 9(2), article 6. doi: 10.5817/CP2015-2-6

\title{
The relationship between Facebook attachment and obsessive- compulsive disorder severity
}

\author{
Soon-Li Lee ${ }^{1}$, Miriam Sang-Ah Park², Cai-Lian Tam³ \\ 1,2,3 School of Medicine and Health Sciences, Monash University, Malaysia
}

\begin{abstract}
Despite the widespread use of social networking sites (SNS) such as Facebook, an adequate understanding of their impact on the users' mental health is still lacking. The present study intends to expand on the current understanding of the linkage between social networking site use and mental health. Our study explored how Facebook use may be associated with obsessive-compulsive disorder (OCD), with the inclusion of obsessive-compulsive beliefs as a mediator. One hundred and fifty-six undergraduate students completed the questionnaire given. Overall, Facebook use contributed to OCD severity through obsessive-compulsive beliefs as the mediator. The present study also yielded other relevant results for cyberpsychology that may help pave the way for future studies.
\end{abstract}

Keywords: Facebook, obsessive-compulsive disorder, obsessive beliefs

\section{Introduction}

Facebook as a popular SNS has gained multidisciplinary scholarly attention. Employing various perspectives, its links to culture (e.g. Osmoush, Yaseen, \& Alma'aitah, 2012), education (e.g. Junco, 2012), personality (e.g. Ong et al., 2011), romantic relationship (Elphinston \& Noller, 2011), and mental health (e.g. Rosen, Whaling, Rab, Carrier, \& Cheever, 2013) have been studied. Many of these studies which have related Facebook use with mental health outcomes indicate the significance of this association, and most of the findings suggest a positive relation between heavy usage and mental health issues. Studies have, for example, found significant associations between Facebook use and depression (Moreno, Christakis et al., 2011; Moreno, Jelenchick et al., 2011; Rosen et al., 2013), personality disorders (Rosen et al., 2013), eating disorder (Smith, Hames, \& Joiner, 2013), and compulsive disorder (Rosen et al., 2013).

Most of the published studies focused, however, solely on the link between Facebook use and depression, while studies which include other symptoms or issues are more recent and fewer in number (e.g., Rosen et al., 2013; Smith et al., 2013). These results, however, could not causally explain the link between SNS use and the associated symptoms due to methodological issues. At the present, Rosen et al.'s (2013) study can be seen as the sole effort looking at a variety of clinical symptoms that may be found with heavy Facebook usage. Their study indicated that each of the clinical symptoms covered, including obsessive-compulsive disorder, was associated with Facebook use. Overall, these studies found positive correlation between the use of SNS and the symptoms, which only explained for the simple link between the use of SNS and the symptoms. This could be due to the various clinical symptoms they covered, which limits them from looking into the causes or potential links between them in detail.

Past studies have documented the link between OCD and excessive internet use (Alavi, Maracy, Jannatifard, \& Eslami, 2011; Ha et al., 2007; Jang, Hwang, \& Choi, 2008; Shapira, Goldsmith, Keck, 
Khosla, \& McElroy, 2000). Reflecting from these past findings, a spillover effect can be expected, for Facebook is also a form of online media. Indeed, a study demonstrated that the use of SNS was governed by a strong desire and most individuals failed to engage in self-control when such desire was present (Hofmann, Vohs, \& Baumeister, 2012). From the findings of their study, it can be conjectured that salient desire for media use may be seen to resemble a form of obsession, while the inability to engage in selfcontrol in response to this desire may resemble a form of compulsive behavior.

Unlike previous studies which examined simple correlations for Facebook use and commonly measured symptoms, the present study includes a mediation analysis which may help explain the relationship in more detail. Obsessive beliefs, which have been found as significant mediator in previous research (Inozu, Karanci, \& Clark, 2012; Moulding, Doron, Kyrios, \& Nedeljkovic, 2009), is thus added. The examination of the mediating role for the obsessive beliefs can further illuminate the relationship for Facebook use and OCD severity. Obsessive beliefs were first discussed by the Obsessive Compulsive Cognitions Working Group (OCGWG; 1997; 2001; 2005), with some researchers considering cognitive factors as essentially linked to OCD (e.g. Foa, \& Kozak, 1986; Salkovskis, 1989). Initially, three cognitive factors known as 1) Threat, which refers to overestimation of the potential threat, 2) Perfectionism, which refers to rigidity and high standards of completion, and 3) Control of thoughts, which refers to the need to remove intrusive thoughts, were identified (OCGWG, 2005). An additional factor was added later, which is known as Inflated responsibility, which refers to the urge to prevent negative outcomes (Moulding et al., 2011). These beliefs were directed specifically to OCD and accumulating evidences have supported the link between all of these beliefs with OCD. Studies have documented that direct manipulation on these beliefs significantly affect OCD-like behaviors (e.g. Ladouceur, Rhéaume, \& Aublet, 1997; Ladouceur et al., 1995; Lopatka \& Rachman, 1995; Moulding, Kyrios, Doron, \& Nedeljkovic, 2007; Shafran, 1997). Obsessive beliefs also mediated the relationship between sense/desire of control and OCD severity (Moulding et al., 2009), as well as the relationship between religiosity and obsession (Inozu et al., 2012). Hence, it is possible that one of these beliefs may trigger the urge for SNS use, which eventually leads to a compulsive-like behavior in its use.

Obsessive beliefs may function as the mediators as Hofmann et al. (2012) indicated that the excessive use of SNS was initiated by a form of urge, which is best represented by obsessive beliefs which are stress provoking (e.g. Moulding et al., 2011). Hence, it is suggested that the use of Facebook escalate into a form of OCD through the obsessive beliefs. The present study aims to examine whether the use of SNS predicts the severity of OCD directly or whether this relationship is mediated by obsessive beliefs. For the present attempt, the use of SNS is measured by a standardized scale which is deemed as more accurate in measuring the use of SNS (Anderson, Fagan, Woodnutt, \& Chamorro-Premuzic, 2012).

\section{Method}

\section{Participants}

A total of 156 university students were recruited for the present study. The participants comprised mainly of Malaysian Chinese $(n=116)$, followed by the Malays $(n=26)$, Malaysian Indians $(n=7)$, and those of other ethnicities $(n=7)$. The age range for the participants was $18-24(M=20.85, S D=1.30)$. The present study consisted of 104 female participants (67\%) and 52 male participants (33\%). The participants were recruited on a convenience sampling basis. Upon their agreement to participate, they were given the questionnaire, which were handed back to the researchers upon completion.

\section{Measures}

The demographic part of the questionnaire included age, gender and ethnicity of the participants.

The scales used in the present study were subjected to exploratory factor analysis (EFA). The small amount of missing values found in the scales were imputed with SPSS EM algorithm and the imputed values were rounded to the nearest valid number. Initially, inspections revealed skewness and kurtosis for each item to be in acceptable ranges and there were no univariate or multivariate outliers. The oblique rotation (Direct Oblimin) was chosen for EFA since the components for each scale were suspected to be highly correlated. The extraction of the components was based on Horn's (1965) parallel analysis since the scree plot tends to overestimate the number of components (Hubbard \& Allen, 1987; Zwick \& Velicer, 1986). Items with loading below .30 were suppressed. Following these criteria, the present EFA was performed with 156 participants. 
The intrusiveness of Facebook was measured by the Facebook Intrusion Questionnaire (FIQ; Elphinston \& Noller, 2011) which consists of 8 items. For the present study, the items were rated on a seven-point scale ( $1=$ Strongly disagree, $7=$ Strongly agree). A sample item is "I often use Facebook for no particular reason". The Kaiser-Meyer-Olkin (KMO) was .86, which exceeded the recommended value of .6 (Kaiser, 1970, 1974). Bartlett's test of sphericity, with the $X^{2}(28)=381.18, p<.001$, indicated that the correlations between items were sufficiently large for EFA. The conducted analysis revealed a single component for the FIQ, which accounted for $46.97 \%$ of the variance. The item loadings ranged from .55 to .78. The Cronbach's alpha for these items was .83. With the extraction for a single component, the present EFA replicated the component found by Elphinston and Noller (2011). The score was computed by summing up the ratings for the items. The score range for the present factor is 8-56.

The OCD severity was measured by the Obsessive Compulsive Inventory-Revised (OCI-R; Foa et al. 2002) which consists of 18 items. For the present study, each item was rated on a five-point scale $(0=$ Not at all, 4 = Extremely). A sample item is "I check things more often than necessary". The OCI-R consists of 6 subscales, namely Checking, Hoarding, Neutralizing, Obsessing, Ordering and Washing. The KMO for the OCI-R was .87 and the Bartlett's test of sphericity was significant, with $X^{2}(153)=1280.45, p$ $<.001$. This EFA revealed the presence of four components, which explained for $39.70 \%, 8.65 \%, 7.04 \%$, and $6.29 \%$ of the variances, respectively. The Horn's (1965) parallel analysis, which is more accurate than scree plot in reflecting on the presence of components (Hubbard \& Allen, 1987; Zwick \& Velicer, 1986), suggested for a single component. Thus, the extraction proceeded with a single component, which explained a total of $39.71 \%$ of the variance. The item loadings for the eighteen items ranged from .49 to .70. The Cronbach's alpha for OCI-R was .91. As a single component was extracted, the present EFA failed to replicate the 6 components found by Foa et al. (2002). The final score was computed by summing up the ratings for the items, and the possible score range was 0-72.

Obsessive beliefs were measured by the Obsessive Belief Questionnaire-20 (OBQ-20; Moulding et al., 2011) which consists of 20 items. For the present study, this questionnaire was rated on a seven-point scale ( $1=$ Disagree very much, $7=$ Agree very much). A sample item is "For me, having bad urges is as bad as actually carrying them out". The OBQ-20 consists of 4 subscales, namely Control of Thoughts, Perfectionism, Threat, and Responsibility. The KMO was .89 and the Bartlett's test of sphericity was significant, with $X^{2}(190)=1262.07, p<.001$. The EFA revealed five components which explained for $36.77 \%, 8.18 \%, 6.23 \%, 5.61 \%$, and $5.06 \%$ of the variances respectively. The Horn's (1965) parallel analysis indicated the presence of a single component and the extraction proceeded with a single component which accounted for $36.77 \%$ of the variance. The item loadings ranged from .40 to .73. The Cronbach's alpha for OBQ-20 was .90. As only a single component was extracted, the present EFA failed to replicate the 4 components found by Moulding et al. (2011). The final score was computed by summing up the ratings for the items and the score range was 20-140.

\section{Results}

For the present study, the variables were computed according to the components that were found. The newly computed variables were subjected to assumptions checks. The inspections revealed that the distributions for the intrusiveness of Facebook, OCD severity and obsessive beliefs were normally distributed. Table 1 summarizes the descriptive statistics for the present study. The sequence for the statistical tests performed begins with the test of correlation and mediation testing. Correlations amongst the variables were examined to detect for multicollinearity.

Table 1. Descriptive Statistics.

\begin{tabular}{lcc}
\hline & $\boldsymbol{M}$ & $\boldsymbol{S D}$ \\
\hline Intrusiveness of Facebook & 25.28 & 8.95 \\
OCD severity & 22.73 & 12.94 \\
Obsessive beliefs & 75.24 & 18.43 \\
\hline
\end{tabular}

Pearson's correlations were computed with the intrusiveness of Facebook, OCD severity and obsessive beliefs. As multiple testing increases the risk for committing Type 1 error, Bonferroni adjustment was applied to keep the overall $p$ value at .05 (Curtin \& Schulz, 1998). Thus, the correlations were considered 
significant if the $p$ values were lesser than .017. The intrusiveness of Facebook was significant correlated with OCD severity, $r(153)=.36, p<.001$, and the obsessive beliefs, $r(153)=.22, p<.01$. The OCD severity was significantly correlated with the obsessive beliefs, $r(153)=.52, p<.001$. Overall, the correlations were all significant. Although the correlation between OCD severity and obsessive beliefs was large, it was not sufficient to warrant for multicollinearity. Hence, the present analysis proceeded with MANOVA and mediation analysis.

Subsequently, a mediation analysis was conducted to test for the significance of obsessive beliefs as a mediator for the relationship between the intrusiveness of Facebook and OCD severity. However, the present study did not adhere to Baron and Kenny's (1986) guidelines, as Preacher and Hayes (2004) hold that Baron and Kenny's (1986) guidelines will suffer from low statistical power if performed with a small sample size. In addition, Preacher and Hayes (2004) recommended bootstrapped estimate to be used with small samples with non-normal distribution properties. Hence, the present study used a SPSS macro written by Preacher and Hayes (2004) to test for mediation. This macro allows the estimation for 1) the total effect from predictor variable on criterion variable $\left(B_{\mathrm{YX}}\right) ; 2$ ) the direct effect from the predictor variable on the mediator variable $\left.\left(B_{\mathrm{MX}}\right) ; 3\right)$ the effect from the mediator on the criterion variable, controlling for the predictor variable $\left.\left(B_{\mathrm{YM} . \mathrm{X}}\right) ; 4\right)$ the direct effect from the predictor variable on the criterion variable, controlling for the mediator variable $\left(B_{Y X . M}\right)$, and; 5 ) the indirect effect from the predictor variable on the criterion variable with bootstrapped estimates of $95 \%$ and $99 \%$ confidence interval. The bootstrapped estimate is significant if the lower bounds and the upper bounds for both $95 \%$ and $99 \%$ confidence intervals are greater than zero. For the present study, the bootstrapped ratio of 5000 bootstraps for the indirect effect was used. Therefore, mediation is assumed if 1) there is an effect to be mediated, and 2) the indirect effect is statistically significant in the direction predicted by mediation hypothesis.

In the preliminary analysis, the total effect from the intrusiveness of Facebook on OCD severity was significant $(B=0.53, p<.001)$. The direct effect from the intrusiveness of Facebook on obsessive beliefs was significant as well $(B=0.45, p<.05)$. When the intrusiveness of Facebook was controlled, the effect from obsessive beliefs on OCD severity was significant $(B=0.32, p<.001)$. When obsessive beliefs were controlled, the effect from the intrusiveness of Facebook on OCD severity was significant as well ( $B=$ $0.37, p<.001)$. An indirect effect was found with the estimate of .15, 95\% CI $[0.04,0.26]$ and was thus significant, supporting for the mediating effect from the obsessive beliefs on the relationship between the intrusiveness of Facebook and the severity of OCD. Bi-directionality was tested, which revealed a nonsignificant result. Figure 1 summarizes the complete mediation model.

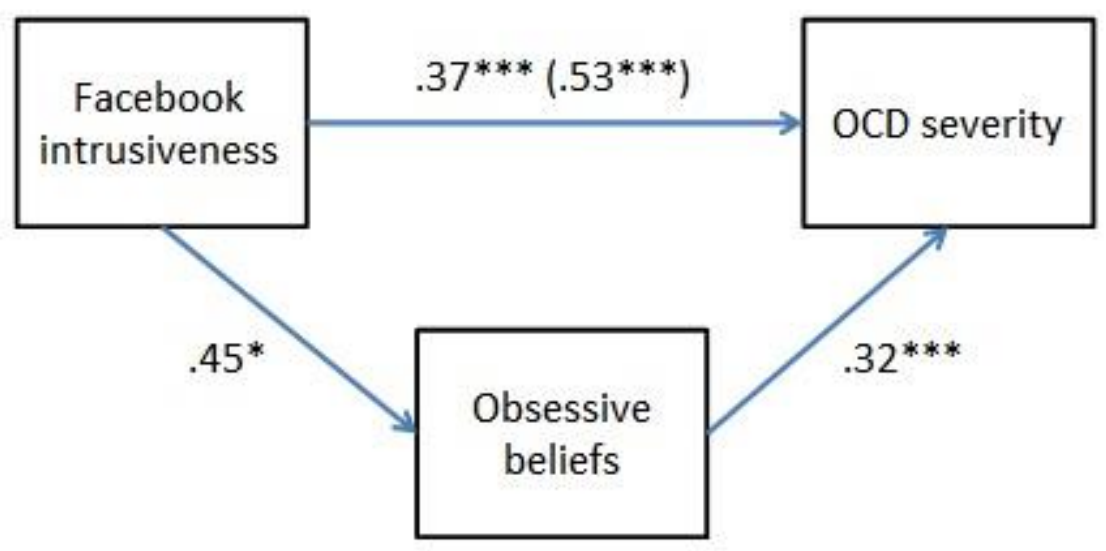

Figure 1. The significant mediation model. Path values represent unstandardized regression coefficients. ${ }^{*} p<.05 . * * p<.01 . * * * p<.001$. Value in brackets is the total effect.

\section{Discussion}

The present study intended to explore the possible association between Facebook use and OCD. In sum, users with high level of Facebook use had significantly higher means for the intrusiveness of Facebook, OCD severity, and obsessive-compulsive beliefs. The positive association between OCD severity and Facebook use was consistent with the past studies on internet use (Alavi et al., 2011; Ha et al., 2007; 
Jang et al., 2008; Shapira et al., 2000). The relationship between Facebook use and OCD severity was found to be mediated by obsessive-compulsive related beliefs. The role of obsessive-compulsive related beliefs as a significant mediator suggests that Facebook use contributes to OCD severity through these beliefs, which often consist of stress inducing beliefs (Moulding et al., 2011). The significant mediation effect found is consistent with Hofmann et al.'s (2012) finding that excessive use of SNS was initiated by an urge. The present findings contributed by adding that the use of Facebook predicted for severity of OCD through obsessive beliefs, which is similar to the urge described by Hoffman et al. (2012). Overall, it was suggested that heavy users were more likely to endorse maladaptive beliefs, such as those illustrated by obsessive beliefs. Hence, upon experiencing the stress induced by the thoughts, heavy users may engage in ritual-like behavior to relieve the anxiety induced by the maladaptive thoughts. This finding highlights the importance of cognitive factors in impacting the relationship between Facebook use and maladaptive symptoms, although we also must note that further research that will re-examine and clarify the directions of the interrelationships is needed. Our findings suggest that the link between Facebook use and clinical symptoms can be complex as such relationship could be dependent on a multitude of factors. This requires further examination from future research.

The present study extends the belief that the use of Facebook may resemble a form of obsessivecompulsive behavior, mediated by obsessive beliefs. Hence, the current findings may indicate that the notion of Facebook addiction is obsolete. The difference between addiction and OCD lies within the outcome for the persisting behavior. Often, repetitive behaviors induced by addiction leads to pleasure or a state of euphoria while those triggered by obsessive thoughts lead to reduction of the discomfort induced by the obsessions (Marks, 1990). Following this distinction, the finding made by Hofmann et al. (2012) reflected on a form of obsession, represented by the strong urge for media use documented. Similarly, the significant mediation model is consistent with the requirements for compulsive behavior outlined by Marks (1990), that anxiety provoking thoughts triggered the relationship between the use of Facebook and severity of OCD. However, it is still premature to conclude that the addictive tendencies towards SNS should be disregarded as the present study did not attempt to differentiate between addiction and OCD. To illuminate the distinction for these two aspects, further attempts to test both addictive tendencies towards SNS and OCD should be made.

In relation to the measurements used, the variance accounted for by the FIQ with the present sample is similar to the findings of the original study, which documented that the same scale accounted for $49.23 \%$ of the variance (Elphinston \& Noller, 2011). However, in our study, the OCI-R and the OBQ-20 were found with less explanatory power, accounting for less variance in the outcome compared to the original findings (Foa et al., 2002; Moulding et al., 2011). Moreover, the outcome of the factor analyses in the present study failed to replicate the original components for the respective scales. This could be due to the small sample size as EFA is sensitive to sample size (Tabachnick \& Fidell, 2007). As the present EFA generated single component structures for both the OCI-R and the OBQ-20, it is equivalent to using the total score for these scales. The use of total score may prevent redundancy (Moulding et al., 2009) since past studies have documented high correlations among the subscales for the OBQ (Woods, Tolin, \& Abramowitz, 2004; Faull, Joseph, Meaden, \& Lawrence, 2004). It is essential for future studies to examine the psychometric properties of these scales more carefully since most of these were not originally intended or validated for non-Western populations.

The present study suffers from a few limitations which should be mentioned. Firstly, the present study could not establish causality since there was no manipulation on the variables. However, direct manipulation of Facebook use could be challenging, since no suggestion on such manipulation is yet available. Although bi-directionality has been tested for, which revealed a non-significant result, it is necessary to interpret the present mediation model carefully as the design employed limit the present study from drawing concrete conclusion. Secondly, the present study did not involve any attempts to clinically diagnose the participants. Hence, it is unknown whether high score on the OCI-R is equivalent to high OCD severity. Moreover, there are other mental health outcomes and variables which may relate to Facebook use such as depression, addictive tendencies and need for connectedness that were not considered in this study. Future studies should further explore such relationships between SNS usage and mental health. The present sample included 156 participants, which is relatively small. In addition, the ethnic distribution and gender of the sample were not equal, making it difficult to generalize the obtained results. 


\section{References}

Alavi, S. S., Maracy, M. R., Jannatifard, F., \& Eslami, M. (2011). The effect of psychiatric symptoms on the internet addiction disorder in Isfahan's university students. Journal of Research in Medical Sciences, 16, 793-800.

Anderson, B., Fagan, P., Woodnutt, T., \& Chamorro-Premuzic, T. (2012). Facebook psychology: Popular questions answered by research. Psychology of Popular Media Culture, 1, 23-37.

http://dx.doi.org/10.1037/a0026452

Baron, R. M., \& Kenny, D. A. (1986). The moderator-mediator variable distinction in social psychological research: Conceptual, strategic, and statistical considerations. Journal of Personality and Social Psychology, 51, 1173-1182. http://dx.doi.org/10.1037/0022-3514.51.6.1173

Curtin, F., \& Schulz, P. (1998). Multiple correlations and Bonferroni's correction. Biological Psychiatry, 44, 775-777. http://dx.doi.org/10.1016/S0006-3223(98)00043-2

Elphinston, R. A., \& Noller, P. (2011). Time to face it! Facebook intrusion and the implications for romantic jealousy and relationship satisfaction. Cyberpsychology, Behavior, and Social Networking, 14, 631-635. http://dx.doi.org/10.1089/cyber.2010.0318

Faull, M., Joseph, S., Meaden, A., \& Lawrence, T. (2004). Obsessive beliefs and their relation to obsessive-compulsive symptoms. Clinical Psychology and Psychotherapy, 11, 158-167.

http://dx.doi.org/10.1002/cpp.403

Foa, E. B., \& Kozak, M. J. (1986). Emotional processing of fear. Psychological Bulletin, 99, 20-35.

Foa, E. B., Huppert, J. D., Leiberg, S., Langner, R., Kichic, R., Hajcak, G., \& Salkovskis, P. M. (2002). The Obsessive-Compulsive Inventory: Development and validation of a short version. Psychological

Assessment, 14, 485-496. http://dx.doi.org/10.1037/1040-3590.14.4.485

Ha, H. H., Kim, S. Y., Bae, S. C., Bae, S., Kim, H., Sim, M., . . Cho, S. C. (2007). Depression and internet addiction in adolescents. Psychopathology, 40, 424-430. http://dx.doi.org/10.1159/000107426

Hofmann, W., Vohs, K. D., \& Baumeister, R. F. (2012). What people desire, feel conflicted about, and try to resist in everyday life. Psychological Science, 23, 582-588.

http://dx.doi.org/10.1177/0956797612437426

Horn, J. L. (1965). A rationale and test for the number of factors in factor analysis. Psychometrika, 30, 179-185. http://dx.doi.org/10.1007/BF02289447

Hubbard, R., \& Allen, S. J. (1987). An empirical comparison of alternative methods for principal component extraction. Journal of Business Research, 15, 173-190. http://dx.doi.org/10.1016/01482963(84)90047-X

Inozu, M., Karanci, A. N., \& Clark, D. A. (2012). Why are religious individuals more obsessional? The role of mental control beliefs and guilt in Muslims and Christians. Journal of Behavior Therapy and Experimental Psychiatry, 43, 959-966. http://dx.doi.org/10.1016/j.jbtep.2012.02.004

Jang, K. S., Hwang, S. Y., \& Choi, J. Y. (2008). Internet addiction and psychiatric symptoms among Korean adolescents. Journal of School Health, 78, 165-171. http://dx.doi.org/10.1111/j.17461561.2007.00279.x

Junco, R. (2012). Too much face and not enough book: The relationship between multiple indices of Facebook use and academic performance. Computers in Human Behavior, 28, 187-198.

http://dx.doi.org/10.1016/j.chb.2011.08.026

Kaiser, H. (1970). A second generation Little Jiffy. Psychometrika, 35, 401-415.

http://dx.doi.org/10.1007/BF02291817 
Kaiser, H. (1974). An index of factorial simplicity. Psychometrika, 39, 31-36.

http://dx.doi.org/10.1007/BF02291575

Ladouceur, R., Rhéaume, J., \& Aublet, F. (1997). Excessive responsibility in obsessional concerns: A finegrained experimental analysis. Behaviour Research and Therapy, 35, 423-427.

http://dx.doi.org/10.1016/S0005-7967(96)00117-9

Ladouceur, R., Rhéaume, J., Freeston, M. H., Aublet, F., Jean, K., Lachance, S., . . De PokomandyMorin, K. (1995). Experimental manipulations of responsibility: An analogue test for models of ObsessiveCompulsive Disorder. Behaviour Research and Therapy, 33, 937-946. http://dx.doi.org/10.1016/00057967(95)00024-R

Lopatka, C., \& Rachman, S. (1995). Perceived responsibility and compulsive checking: An experimental analysis. Behaviour Research and Therapy, 33, 673-684. http://dx.doi.org/10.1016/0005-

7967(94)00089-3

Marks, I. (1990). Behavioural (non-chemical) addictions. British Journal of Addiction, 85, 1389-1394. http://dx.doi.org/10.1111/j.1360-0443.1990.tb01618.x

Moreno, M. A., Christakis, D. A., Egan, K. G., Jelenchick, L. A., Cox, E., Young, H., . . Becker, T. (2011). A pilot evaluation of associations between displayed depression references on Facebook and self-reported depression using a clinical scale. Journal of Behavioral Health Services and Research, 39, 295-304. http://dx.doi.org/10.1007/s11414-011-9258-7

Moreno, M. A., Jelenchick, L. A., Egan, K. G., Cox, E., Young, H., Gannon, K. E., \& Becker, T. (2011). Feeling bad on Facebook: Depression disclosures by college students on a social networking site. Depression and Anxiety, 28, 447-455. http://dx.doi.org/10.1002/da.20805

Moulding, R., Anglim, J., Nedeljkovic, M., Doron, G., Kyrios, M., \& Ayalon, A. (2011). The Obsessive Beliefs Questionnaire (OBQ): Examination in nonclinical samples and development of a short version. Assessment, 18, 357-374. http://dx.doi.org/10.1177/1073191110376490

Moulding, R., Doron, G., Kyrios, M., \& Nedeljkovic, M. (2009). Mediated and direct effects of general control beliefs on obsessive compulsive symptoms. Canadian Journal of Behavioural Science, 41, 84-92. http://dx.doi.org/10.1037/a0014840

Moulding, R., Kyrios, M., Doron, G., \& Nedeljkovic, M. (2007). Autogenous and reactive obsessions: Further evidence for a two-factor model of obsessions. Journal of Anxiety Disorders, 21, 677-690. http://dx.doi.org/10.1016/j.janxdis.2006.10.001

Obsessive Compulsive Cognitions Working Group. (1997). Cognitive assessment of obsessive-compulsive disorder. Behaviour Research and Therapy, 35, 667-681.

Obsessive Compulsive Cognitions Working Group. (2001). Development and initial validation of the obsessive beliefs questionnaire and the interpretation of intrusions inventory. Behaviour Research and Therapy, 39, 987-1006.

Obsessive Compulsive Cognitions Working Group. (2005). Psychometric validation of the obsessive belief questionnaire and interpretation of intrusions inventory-Part 2: Factor analyses and testing of a brief version. Behaviour Research and Therapy, 43, 1527-1542

Ong, E. Y., Ang, R. P., Ho, J., Lim, J. C., Goh, D. H., Lee, C. S., \& Chua, A. Y. (2011). Narcissism, extraversion and adolescents' self-presentation on Facebook. Personality and Individual Differences, 50, 180-185. http://dx.doi.org/10.1016/j.paid.2010.09.022

Osmoush, K. S. A., Yaseen, S. G., \& Alma'aitah, M. A. (2012). The impact of Arab cultural values on online social networking: The case of Facebook. Computer in Human Behavior, 28, 2387-2399.

http://dx.doi.org/10.1016/j.chb.2012.07.010 
Preacher, K. J., \& Hayes, A. F. (2004). SPSS and SAS procedures for estimating indirect effects in simple mediation models. Behavior Research Methods, Instruments, \& Computers, 36, 717-731.

http://dx.doi.org/10.3758/BF03206553

Rosen, L. D., Whaling, K., Rab, S., Carrier, L. M., Cheever, N. A. (2013). Is Facebook creating "iDisorder"? The link between clinical symptoms of psychiatric disorders and technology use, attitudes and anxiety. Computers in Human Behavior, 29, 1243-1254. http://dx.doi.org/10.1016/j.chb.2012.11.012

Salkovskis, P. M. (1989). Cognitive-behavioural factors and the persistence of intrusive thoughts in obsessional problems. Behaviour Research and Therapy, 27, 677-682. http://dx.doi.org/10.1016/00057967(89)90152-6

Shafran, R. (1997). The manipulation of responsibility in obsessive-compulsive disorder. British Journal of Clinical Psychology, 36, 397-407. http://dx.doi.org/10.1111/j.2044-8260.1997.tb01247.x

Shapira, N. A., Goldsmith, T. D., Keck, P. E., Khosla, M. U., \& McElroy, S. L. (2000). Psychiatric features of individuals with problematic internet use. Journal of Affective Disorders, 57, 267-272.

http://dx.doi.org/10.1016/S0165-0327(99)00107-X

Smith, A. R., Hames, J. L., \& Joiner Jr, T. E. (2013). Status update: Maladaptive Facebook usage predicts increases in body dissatisfaction and bulimic symptoms. Journal of Affective Disorders, 149, 235-240. http://dx.doi.org/10.1016/j.jad.2013.01.032

Tabachnick, B. G., \& Fidell, L. S. (2007). Using multivariate statistics (5th ed.). Boston: Pearson Education.

Woods, C. M., Tolin, D. F., \& Abramowitz, J. S. (2004). Dimensionality of the obsessive beliefs questionnaire (OBQ). Journal of Psychopathology and Behavioral Assessment, 26, 113-125.

http://dx.doi.org/10.1023/B:JOBA.0000013659.13416.30

Zwick, W. R., \& Velicer, W. F. (1986). Comparison of five rules for determining the number of components to retain. Psychological Bulletin, 99, 432-442. http://dx.doi.org/10.1037/0033-2909.99.3.432

\section{Correspondence to:}

Soon-Li Lee

Jalan Lagoon Selatan

Bandar Sunway

47500 Subang Jaya

Selangor, Malaysia

Email: sllee22(at)student.monash.edu 


\section{About authors}

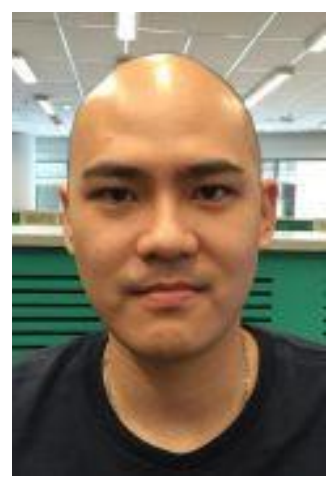

Soon Li, Lee is a PhD candidate at Monash University Malaysia. His research interests include the influence of social networking sites on the users' well-being, and psychometrics.

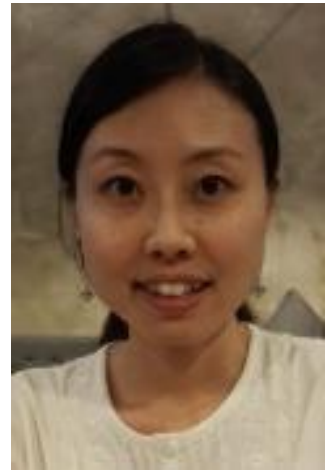

Dr. Miriam Sang-Ah Park obtained her Bachelor of Science (BSc) with a major in Psychology from University of Toronto, Canada, where she developed particular interests in sociocultural influences on the selfhood, perceptions and general beliefs. She undertook her PhD studies under the supervision of Professor Robin Goodwin at Brunel University, London, UK. Her primary areas are social, (cross-) cultural and political psychology, and her research focuses on topics such as social change and its implications for individual values, family views and political beliefs, cultural orientations and self-construals, and family democratisation in different societies.

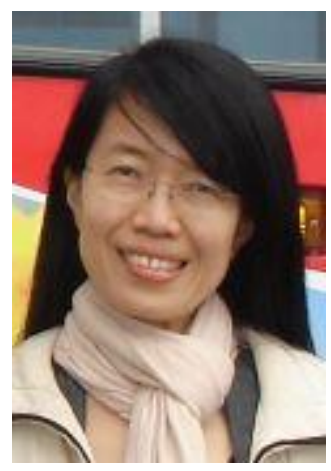

Dr. Tam Cai Lian is the Senior Lecturer and a licensed counselling psychologist from Monash University Malaysia. She is a registered counsellor from the Board of Counsellors Malaysia with special interest in the variety of challenges facing adolescents in Malaysia. Currently, Dr. Tam is the advisor for People Development Counselling (PDC) and the coordinator for the Master of Professional Counselling for Monash University Malaysia. She has involved actively in conducting research and providing consultation related with coping and relaxation skills. 